\title{
Impact of Empowerment on Employee Turnover Intention: The Influence of Job Satisfaction
}

\author{
Amjad Ali \\ School of Management \\ Fujian Agriculture and Forestry University \\ Fuzhou 350002, China \\ amjad_jamy81@yahoo.com \\ Zulfiqar Ali \\ School of Management \\ Fujian Agriculture and Forestry University \\ Fuzhou 350002, China \\ zulfiqar3344@yahoo.com
}

\author{
Huang JianPing \\ School of Management \\ Fujian Agriculture and Forestry University \\ Fuzhou 350002, China \\ nine_01@126.com \\ Li ZhongBin* \\ School of Management \\ Fujian Agriculture and Forestry University \\ Fuzhou 350002, China \\ *Corresponding author: lzb15592@yahoo.com
}

\begin{abstract}
Recent studies show that the intention of manufacturing employee turnover remains a major problem in emerging economies. In particular, a lack of empowerment and job satisfaction means that the turnover of Pakistani employees in manufacturing firms remains high. This study investigates the mediating impact of job satisfaction on the relationship between empowerment and turnover intention. A purposive sample of 315 participants from the agricultural manufacturing industry in the region of Khyber Pakhtunkhwa Province, Pakistan, was selected for the study, and a cross-sectional survey was conducted. A selfadministrated survey questionnaire was distributed, and participants were asked to respond on a five-point Likert scale to questions regarding empowerment, job satisfaction, and turnover intention. SEM/SPSS were employed to analyze the data. Furthermore, a statistical analysis was conducted to test the mediating effects of job satisfaction on the relationship between empowerment and turnover intention. For the full mediating impact of job satisfaction on the relationship between empowerment and turnover intention, we obtained statistically significant results. Our study also determined a significant negative direct relationship between empowerment and turnover intention. Thus, job satisfaction not only significantly influences turnover intention, but also mediates the relationship between empowerment and turnover intention. The findings of this study contribute to the literature on turnover intention in the agricultural manufacturing industry by increasing understanding of the impact of job satisfaction and empowerment on turnover intention among manufacturing employees. This research provides important policy insights for managers in manufacturing industries seeking to increase empowerment and job satisfaction among their employees to reduce turnover intention.
\end{abstract}

Keywords-Employee Empowerment; Job Satisfaction; Turnover Intention

\section{INTRODUCTION}

Empowerment is considered an effective management practice that describes the outcomes of work, because empowered individuals are more likely to be satisfied with their work and perform well in an organization. Empowerment is regarded as a feeling of personal power and control [1], and considered an important component of high performance practices. Psychological aspects of the concept of empowerment include the individual's personal and inner experiences. Empowered employees choose their own procedures and stay devoted to them. Kim, Kumar and Kumar [2] determined that empowered employees are highly efficient and effective in their work, more motivated to experience new things, able to cope with diversity, and ready to make major changes when asked to do so. Employee empowerment provides the autonomy to make decisions and allows individuals to participate in organizational decisions regarding their daily activities [3]. Hence, employee empowerment is described as the transfer of decision-making power or decentralization. This is not just the transfer of power, but also supports the transfer of power by providing the necessary knowledge, skills, and resources for its effective implementation.

Velthouse and Thomas [4] argues that empowered employees feel they have control over the main portions of their work; thus, they are more committed, optimistic, and concerned, and may be less likely to quit their work than nonempowered workforces. This is because staff like or enjoy greater autonomy in the workplace and have little chance of withdrawal or alienation. However, empowerment is contextual, which is a social construct depending on how individuals integrate their perceptions of personal control, proactive lifestyles, and understanding of the social and political environments [5]. Therefore, empowerment can be viewed differently across cultures, meaning that the success of empowerment as a managerial practice lies in the proper understanding of culture based on the beliefs, assumptions, and values held by those being managed. In particular, empowerment is incongruence between cultural values and management practices, which may impact power distance, 
especially when subordinates are accustomed to receiving orders from their managers without any questions [6].

However, the extant literature indicates a lack of empirical evidence for the relationship between empowerment, job satisfaction, and turnover intention. Therefore, the aim of this study is to provide a more comprehensive picture of how empowerment practices are linked to the job satisfaction of employees in Pakistani agricultural manufacturing firms to predict their turnover intention. This is important for manufacturing firms, because they reflect employee performance quality. Consequently, this research attempts to promote theoretical development by providing empirical evidence of hypothetical relations. In addition, most existing research on this subject was conducted in Western countries. The present study clarifies these constructs in the context of Asia, specifically in Pakistan, which is dominated by a collectivist culture. The indigenous nature of the country makes the existing research important, as culturally, Pakistan is a collectivist society [7].

Eastern and Western societies differ in their views on empowerment, as the Western culture promotes and advocates democracy [8]. However, empowerment is controversial in Asian societies that conventionally stimulate the culture of tolerance, compliance, modesty, and hierarchy. Therefore, positioning this study here may reveal unusual results. Although some research has been conducted on job satisfaction and turnover intention, there is a lack of important work on the relationships between these constructs and empowerment. The purpose of the research is to analyze the (positive and negative) impacts of empowerment on job satisfaction and turnover intention. In addition, job satisfaction can mediate the influence of empowerment on turnover intention.

\section{METHOD}

\section{A. Procedure and method}

Data gathered for this study was collected from employees in agricultural manufacturing firms in Khyber Pakhtunkhwa Province, Pakistan, through a self-administered questionnaire. For sample selection, convenience sampling was utilized. In total, 400 anonymous survey questionnaires were circulated to employees. Respondents were approached after obtaining the permission of their HR departments, and informed that this task would not take more than 30 minutes. Furthermore, the research aims and ethical issues were discussed with them. Ultimately, 315 usable survey questionnaires were received, yielding a valid response rate of $79 \%$. Of the 315 participants who constituted the final sample, 265 (84.1\%) were males, and 50 (15.9\%) were females. Most participants were aged between 20 and 30 years (56.5\%), followed by those aged between 31 and 40 years (37.1\%) years, and those older than 41 years (6.3\%). Regarding education, $18.7 \%$ of the participants completed high school, 6\% completed a diploma, 38.1\% completed a bachelor's degree, 32.7\% completed a master's degree, and $4.4 \%$ completed an M.Phil. Degree. Based on participants' work experience in their current organization, $16.5 \%$ had more than 10 years of experience in their existing organization, $23.5 \%$ had 5 to 10 years experience, $43.2 \%$ had 1 to 5 years experience, while the remaining $16.8 \%$ of participants had less than 1 year of experience in their current organization.

\section{B. Measures}

First, all items were measured on a five-point Likert scale ranging from " 1 = Strongly disagree" to " 5 = Strongly agree." Second, the following measures were used in this research:

Employee empowerment. The five-item scale developed by Men [9] was used to measure employees' perception of empowerment at their work place.

Job satisfaction. Job satisfaction was measured using a four-item scale developed by Sabri, Ilyas and Amjad [10].

Turnover intention. A three-item scale was adapted from Cammann, Fichman, Jenkins and Klesh [11] to measure the turnover intention variable.

\section{Data analysis}

This study employed structural equation modeling (SEM) using the AMOS 21 software to analyze the collected data. SEM is a multivariate statistical procedure employed to confirm the underlying relations between latent variables. The main advantages of SEM include that the method can be used to assess relationships between observed and latent constructs, prove the validity and reliability of constructs, calculate the fitness of a model (in other words, fit the data to the theoretical model), and assess multiple relations at a single point of activity. To calculate the hypothesized model, a two-step procedure proposed and developed by Anderson and Gerbing [12] was adapted to analyze the mediating effect. To ensure the structural relationships of the latent structured model, a confirmatory factor analysis (CFA) was first performed to evaluate the distinctiveness of the measurement components of the model, and then the structural model was estimated. In addition, a bootstrapping technique was employed to confirm the significance of indirect effects [13].

\section{Reliability and validity}

To confirm the internal consistency between items, Cronbach's alphas and composite reliabilities were calculated. In this study, the reliability for all variables was found to be acceptable, as the values scored more than 0.70, which indicates sufficient internal consistency reliability. We also calculated convergent and discriminant validity to check constructs validity by using the procedure suggested by Fornell and Larcker [14]. Convergent validity was confirmed, as the factor loadings for all indicators of the latent constructs were statistically significant at the 0.001 level, exceeding the recommended threshold value of 0.5 . In addition, discriminant validity was supported using the method of the AVE square root of each construct compared to the inter-construct correlation. The AVE of each variable should be greater than its squared correlation with other constructs. The results indicate that the square root of the AVE of each construct is greater than its correlation with all other constructs, thereby validating discriminant validity. Reliabilities, validities, and factor loadings for all three variables are presented in Table 1. 
TABLE I. RELIABILITIES, VALIDITIES AND FACTOR LOADINGS

\begin{tabular}{|c|c|c|c|}
\hline Measures & Cronbach's $\alpha$ & $\begin{array}{l}\text { Composite } \\
\text { Reliability }\end{array}$ & $\begin{array}{l}\text { Standardized } \\
\text { Factor } \\
\text { Loadings* }\end{array}$ \\
\hline $\begin{array}{c}\text { Employee } \\
\text { Empowerment }\end{array}$ & 0.859 & 0.861 & \\
\hline EE1 & & & $0.71^{* * *}$ \\
\hline EE2 & & & $0.83^{* * *}$ \\
\hline EE3 & & & $0.75^{* * *}$ \\
\hline EE4 & & & $0.77^{* * *}$ \\
\hline EE5 & & & $0.65^{* * *}$ \\
\hline Job Satisfaction & 0.885 & 0.889 & \\
\hline JS1 & & & $0.84 * * *$ \\
\hline JS2 & & & $0.71^{* * *}$ \\
\hline JS3 & & & $0.82^{* * *}$ \\
\hline JS4 & & & $0.89 * * *$ \\
\hline $\begin{array}{l}\text { Turnover } \\
\text { Intention }\end{array}$ & 0.779 & 0.818 & \\
\hline TI1 & & & $0.51^{* * *}$ \\
\hline TI2 & & & $0.98^{* * *}$ \\
\hline TI3 & & & $0.79 * * *$ \\
\hline $\begin{array}{c}\text { Average Variance } \\
\text { Extracted(AVE) }\end{array}$ & 0.554 & 0.669 & 0.615 \\
\hline
\end{tabular}

\section{E. Measurement model}

First, CFA was conducted using AMOS 21.0 to verify the adequacy of the measurement model. We employed a threefactor measurement model in which three latent variables (employee empowerment, job satisfaction, turnover intention) and 12 observed variables were included. As recommended by Hair, Anderson, Tatham and Black [15], multiple fit criteria, the Chi square $X^{2}$, adjusted goodness-of-fit index (AGFI), goodness-of-fit index (GFI), Tucker-Lewis index (TLI), comparative fit index (CFI), and the root-means-square error of approximation (RMSEA) were used to verify the overall fit of the models. For the CFI, TLI, and GFI, the recommended cutoff values should exceed or be close to 0.90, and for the AGFI, the critical threshold value should be greater than 0.80 . Finally, for the RMSEA, the cut-off value of 0.08 or less was considered an acceptable fit [15]. Thus, the initial results of the three-factor measurement model indicated a satisfactory fit with the data $\left(\mathrm{X}^{2}=116.096, \mathrm{df}=51, \mathrm{P}>0.05, \mathrm{X}^{2} / \mathrm{df}=2.276\right.$, AGFI=0.906, GFI $=0.938, \quad \mathrm{CFI}=0.968, \quad \mathrm{TLI}=0.958$, and RMSEA = 0.064). Moreover, all factor loadings were statistically significant $(\mathrm{P}<0.001)$ for all indicators of the latent constructs, providing evidence of convergent validity.

\section{F. Structural model}

After obtaining satisfactory results for the CFA, SEM was employed to analyze the mediating effect of the proposed model. First, we tested the fully mediated model without the direct paths from empowerment to turnover intention. The results demonstrated that the model met the recommended levels of good fit, as the $\mathrm{X}^{2}$ values were statistically significant $\left(X^{2}=132.826, \quad \mathrm{df}=54, \quad \mathrm{P}=0.00, \quad \mathrm{X}^{2} / \mathrm{df}=2.46, \quad\right.$ AGFI=0.906, GFI=0.938, RMSEA=0.064, CFI=0.968, TLI=0.938). Next, we tested a partially mediated model to assess additional direct paths from empowerment to turnover intention. The results yielded the following values: $\mathrm{X}^{2}=131.636, \mathrm{df}=52, \mathrm{P}<0.001$, and $\mathrm{X}^{2} / \mathrm{df}=2.531$, which were similar to the results of the fully mediated model ( $\mathrm{X}^{2}$, the AGFI, GFI, RMSEA, TLI, and CFI values were $0.906,0.938,0.064,0.938$, and 0.968 respectively). Therefore, the results show that the two models - the fully mediated and partially mediated models-have similar fit to the data. Thus, an $\mathrm{X}^{2}$ differential test was conducted to compare the two models. The $\Delta \mathrm{X}^{2}=1.14$ and $\Delta \mathrm{df}=2$ between the two models, resulting in a value of 0.57 , which is less than the recommended threshold value of 3.84 [15]. The results demonstrate that the difference is not significant when adding an additional direct path to the partially mediated model. Therefore, the fully mediated model is considered accurate.

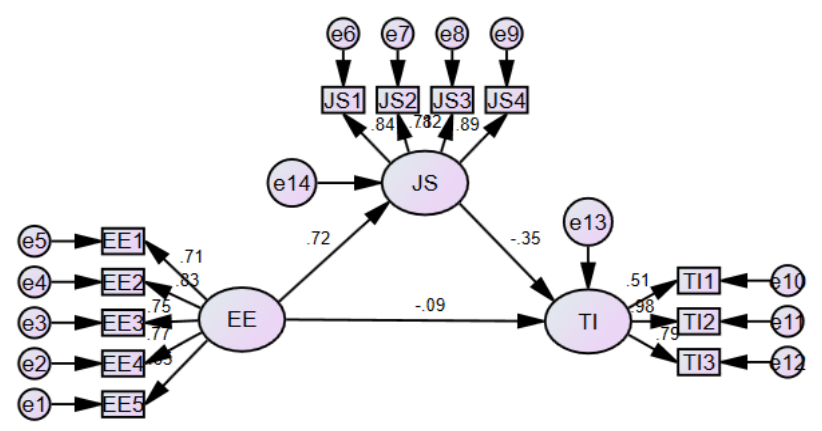

Fig. 1. Structure Model

\section{G. Results}

The mean, standard deviation, and correlation for the three variables are provided in Table 2 . The results indicate that empowerment is significantly negatively correlated with turnover intention $(\mathrm{r}=0.278, \mathrm{p}<0.01)$ and significantly positively correlated with job satisfaction ( $\mathrm{r}=0.625, \mathrm{p}<0.01)$. Furthermore, job satisfaction is significantly negatively related with turnover intention ( $\mathrm{r}=0.314, \mathrm{p}<0.01)$. Therefore, hypothesis 1 was supported.

TABLE II. MEAN, STANDARD DEVIATIONS, AND CORRELATIONS OF THE VARIABLES OF INTEREST

\begin{tabular}{|c|r|r|r|r|r|}
\hline & Mean & SD & 1 & 2 & 3 \\
\hline $\begin{array}{c}\text { Employee } \\
\text { Empowerment }\end{array}$ & 3.87 & 0.729 & 1 & & \\
\hline Job Satisfaction & 3.78 & 0.83 & $\begin{array}{c}0.625 \\
* *\end{array}$ & 1 & \\
\hline $\begin{array}{c}\text { Turnover } \\
\text { Intention }\end{array}$ & 2.8 & 0.993 & $\begin{array}{c}-0.278 \\
* *\end{array}$ & $\begin{array}{c}-0.314 \\
* *\end{array}$ & 1 \\
\hline \multicolumn{7}{|c|}{${ }^{* *} \mathrm{p}<0.01$} \\
\hline
\end{tabular}


The mediating effect of job satisfaction between empowerment and turnover intention was assessed for statistical significance using the bootstrap procedure of Preacher and Hayes (2008). The analysis was run in AMOS (we first specified a bootstrap sample of 2000). We calculated the standardized coefficients and standard error for the one indirect effect. The result yielded for the indirect effect (empowerment-job satisfaction-turnover intention) for the standardized coefficient was -0.197 , with the standard error of 0.078. For the indirect effect, the estimate of $95 \% \mathrm{CI}$ (confidence interval) ranged from -0.362 to -0.584 . Zero was not present in the CIs. Therefore, the results indicate that the mean of the indirect effect of empowerment on turnover intention through job satisfaction was significant from zero at the level of 0.001 . Thus, hypothesis 2 was supported. However, the other direct effect (empowerment-job satisfaction) was significant with a standardized coefficient $=0.712$ and $\mathrm{p}$-value $<0.001$, and the direct effect of job satisfaction on turnover intention was also significant (standardized coefficient $=-0.276$ and p-value $<0.001$ ).

\section{DISCUSSION}

The literature on empowerment in Pakistan's organizational environment has not yet been developed, although in Western countries, empowerment is generally considered to encourage unexplored human resources. However, some scholars believe that empowerment may be ineffective in collectivist cultures; therefore, Western management perceptions may not be beneficial for the Pakistani workforce [16]. As such, the aim of this research was to examine the impact of empowerment on employee turnover intention through job satisfaction in the agricultural manufacturing industry in Khyber Pakhtunkhwa Province, Pakistan. Our study determined that empowerment had a significant negative impact on turnover intention, a finding supported by previous research $[17,18]$. We also found that on their own, observed empowerment practices can lead to low turnover intention among workers in Pakistani manufacturing firms (Hypothesis 1). Thus, the results indicate that empowerment is directly related to turnover intention among the employees of Pakistani agricultural manufacturing firms. Therefore, this study suggests that managers should understand that an empowerment plan could be used to prevent staff turnover. However, if the plan is not properly designed to increase empowerment, the effect will be questionable. When employees feel empowered, job burnout and job stress are minimized, thereby increasing employees' commitment and job satisfaction.

Furthermore, our research found that the mediating effect of job satisfaction is a tool that supports empowerment and reduces the turnover intention of employees in Pakistani manufacturing firms (Hypothesis 2). While supervisors use empowerment to enable employees to solve problems by themselves, they must also promote job satisfaction to confirm the influence of empowerment on employees' turnover intention in Pakistani manufacturing firms. In other words, Pakistani management should develop a positive working attitude through procedures such as broader and enhanced communication for empowerment and provide stronger supervisor and organizational backing and support. Workers who are not empowerment may not have high job satisfaction and may make less effort compared to those who are highly empowered and likely to remain in the organization for a longer period.

Satisfaction and commitment are related to an organization's work environment. By sharing rituals or values and giving employees a sense of belonging, they feel more emotionally attached to their organization. Furthermore, Pakistani people are sensitive to acquiring or taking, giving, protecting, or gaining face in a social environment. This protocol demonstrates a high degree of hierarchical association between subordinates and superiors. Managers should learn to encourage different opinions and ideas to increase the satisfaction and commitment of employees in Pakistan. Managers must listen to employees' voices, and their contributions influence the performance of their organization.

In short, if Pakistani employees have good relationships in their workplace, they tend to demonstrate more conducive work attitudes and behaviors. While emphasizing satisfaction, empowerment will be more effective in minimizing turnover intention. Managers must empower employees to provide them with an appropriate work environment to improve their satisfaction and reduce turnover intention. In an organization, employee turnover intention can be reduced by encouraging and introducing incentives, pay increases, additional benefits, authority, and promotion.

Finally, the limitations of the study and impact on future research are considered. First, one limitation of the current research is its cross-sectional design. Future research should employ longitudinal research, which will be the best way to analyze relationships and reach more valid conclusions. Another limitation is that data analysis was based on the agricultural manufacturing industry in Pakistan, which limits the generalizability of our findings. Therefore, future research should examine other sectors to increase the possibility of generalization. Finally, the influence of two variables on turnover intention was investigated. Therefore, future research should include other variables such as job security, leadership style, and work environment in its examination.

In conclusion, our study found that Pakistani employees accept empowering management practices and exhibit greater job satisfaction; thus, empowerment decreases employee turnover intention. In addition, a causal mediation analysis was conducted to investigate whether job satisfaction mediates the relationship between empowerment and turnover intention. However, a direct relationship between empowerment and turnover intention was found to be significantly negative. This research also demonstrated job satisfaction as an essential factor in reducing turnover intention. Thus, job satisfaction not only significantly influences turnover intention, but also mediates the relationship between empowerment and turnover intention. The findings of this study will help Pakistani managers implement effective empowerment strategies, and become an empirical study for use by future researchers. 


\section{REFERENCES}

[1] W. Chen, Y. Wu, Y. Yue, J. Liu, W. Zhang, X. Yang, H. Chen, E. Bi, I. Ashraful, M. Grätzel, Efficient and stable large-area perovskite solar cells with inorganic charge extraction layers, Science, 350 (2015) 944948.

[2] D.-Y. Kim, V. Kumar, U. Kumar, Relationship between quality management practices and innovation, Journal of Operations Management, 30 (2012) 295-315.

[3] A. Fatima, M.Z. Iqbal, R. Imran, Organizational commitment and counterproductive work behavior: role of employee empowerment, in: Proceedings of the Sixth International Conference on Management Science and Engineering Management, Springer, 2013, pp. 665-679.

[4] B.A. Velthouse, K.W. Thomas, Cognitive elements of empowerment: an "interpretive" model of intrinsic task motivation, Academy of management Review, 15 (1990) 666-681.

[5] R.D. Zimmerman, UNDERSTANDING THE IMPACT OF PERSONALITY TRAITS ON INDIVIDUALS'TURNOVER DECISIONS: A META - ANALYTIC PATH MODEL, Personnel Psychology, 61 (2008) 309-348.

[6] H. Fock, M. Hui, K. Au, From discretion to psychological empowerment: a cross cultural study for service industry, in: American Marketing Association Conference Proceedings, 2002, pp. 71-79.

[7] G.H. Hofstede, G. Hofstede, Culture's consequences: Comparing values, behaviors, institutions and organizations across nations, Sage, 2001.

[8] K.-s. Yip, The empowerment model: A critical reflection of empowerment in Chinese culture, Social Work, 49 (2004) 479-487.

[9] L. Men, Measuring the impact of leadership style and employee empowerment on perceived organization reputation, University of Miami, Submitted to the Institute of Public Relations, (2010).
[10] P.S.U. Sabri, M. Ilyas, Z. Amjad, Organizational culture and its impact on the job satisfaction of the University teachers of Lahore, International Journal of Business and Social Science, 2 (2011).

[11] C. Cammann, M. Fichman, D. Jenkins, J. Klesh, The Michigan organizational assessment questionnaire, Unpublished manuscript, University of Michigan, Ann Arbor, (1979).

[12] J.C. Anderson, D.W. Gerbing, Structural equation modeling in practice: A review and recommended two-step approach, Psychological bulletin, 103 (1988) 411.

[13] K.J. Preacher, A.F. Hayes, Asymptotic and resampling strategies for assessing and comparing indirect effects in multiple mediator models, Behavior research methods, 40 (2008) 879-891.

[14] C. Fornell, D.F. Larcker, Evaluating structural equation models with unobservable variables and measurement error, Journal of marketing research, (1981) 39-50.

[15] J. Hair, R. Anderson, R. Tatham, W. Black, Multivariate data analysis. Prentice-Hall: Upper Saddle River, NJ Google Scholar, (1998).

[16] C. Robert, T.M. Probst, J.J. Martocchio, F. Drasgow, J.J. Lawler, Empowerment and continuous improvement in the United States, Mexico, Poland, and India: Predicting fit on the basis of the dimensions of power distance and individualism, Journal of applied psychology, 85 (2000) 643.

[17] S. Kim, Factors affecting state government information technology employee turnover intentions, The American Review of Public Administration, 35 (2005) 137-156.

[18] R.M. Ingersoll, Teacher turnover and teacher shortages: An organizational analysis, American educational research journal, 38 (2001) 499-534. 